\title{
PERFORMANCE AND FUEL CONSUMPTION OPTIMIZATIONS OF SHUNTING HYBRID LOCOMOTIVES
}

In recent years hybrid electric drive has become very popular in public transportation and automobiles. This article deals with hybrid drive technology and its impact on performance and energy consumption optimization of shunting locomotives in comparison with conventional diesel-electric locomotives. Based on classic longitudinal train dynamics theory of train movement and with support of simulation results, a comparison of electrochemical accumulators and super-capacitors impact is also introduced.

Keywords: Hybrid drive, shunting locomotive, energy savings, accumulator, supercapacitor.

\section{Introduction}

Hybrid electric drive (HEV) became a very popular alternative of conventional drives last years. We can see many hybrid vehicles for personal use but its popularity is not motivated by energy or fuel savings. The configuration of these vehicles is not optimal for general use in combined city and highway operation [1].

With new types of accumulators and with positive costs development of power converters the hybrid technology is being utilized in public transport vehicles as well. Unfortunately, in scope of railway transport there are only several light trains and locomotive prototypes equipped with the hybrid drive.

In this paper we would like to introduce positive impact of vehicle hybridization on fuel consumption in special operational conditions of yard-switching and shunting locomotives.

\section{Energy analysis of train movement}

Energy analysis of a train movement helps us to focus on reasonable train operation types for hybrid drive applications. The key parameter is kinetic energy, being developed with every acceleration and lost when braking [2] and [3].

Based on the analysis published in [4], the train movement model can be described by a longitudinal train dynamics theory based on 3-axes multipoint movement to a single point linear movement simplification with concentrated parameters (multipoint analysis is not necessary for energy computations). Tractive effort covers resistive forces (vehicle resistance $F_{v}$, elevation and curve resistance $F_{e}$ and $F_{c}$, dynamic/inertia force $F_{a}$ - usually expressed by their specific values $p_{v}, p_{e}, p_{c}, p_{a}$ ). From energetics point of view of the longitudinal analysis, we can recognize two main parts of the overall work $A_{r}$ - a kinetic energy $E_{k}$ and a tractive work $A_{t}$.

$$
A_{r}=E_{k}+A
$$

Kinetic energy $E_{k}$ can be written as

$$
E_{k}=\frac{1}{2} \cdot m \cdot \xi \cdot v_{d}^{2}
$$

where $m$ is a mass of the train, $\xi$ is an addition of rotational parts of the vehicle(s) and $v_{d}$ is a speed difference (or final speed when accelerating from zero speed).

Work part of the energy is represented simply by

$$
A_{t}=F_{r} \cdot l=\left(F_{v}+F_{e}+F_{c}\right) \cdot l
$$

Where $l$ is a distance passed by the train and $F_{r}$ is a sum of resistive forces.

The same conditions are valid for the braking period respectively. The only difference to be mentioned is the sign of the tractive work has to be negative, because the kinetic energy is used to cover resistive forces.

$$
A_{b}=E_{k}-A
$$

To simplify the energy investigation, a train mission cycle can be divided into four periods investigated separately:

- Acceleration period

- Constant speed period

- Coasting (similar to the constant speed period)

\footnotetext{
* Matej Pacha ${ }^{1}$, Jiri Stepanek ${ }^{2}$

${ }^{1}$ Faculty of Electrical Engineering, University of Zilina, Slovakia, E-mail: matej.pacha@fel.uniza.sk

${ }^{2}$ CZ LOKO, a.s., Ceska Trebova, Czech Republic
} 
- Braking (deceleration) period

Overall energy analysis is then a simple summary of periods' results mentioned above.

Energy savings during a train movement are dependent on transport requirements such as speed, a number of stops, locomotive power transmission efficiency and type of the rolling stock, or a coasting to constant speed ratio [4]. All these parameters are based on real world conditions and components and they are discussed separately in many publications. Nevertheless, considering equations above we can focus on energy that can be saved without any impact on transport requirements.

In braking period the whole kinetic energy is partially consumed by resistive forces and the rest is usually irreversibly spent in braking system of conventional vehicles. Focusing on this period of train movement, we can define a relative braking work $\beta_{b}[5]$ and [6]:

$$
\beta_{b}=\frac{A_{b}}{A_{t}+A_{b}}
$$

Using formulas from [4] and [5] we can obtain a parametric equation showing most of dependencies
Based on results from (6) and Fig. 1, a conclusion on braking energy can be made. Energy recuperation in general is more effective for high speed short distance trains like city shuttles or public transport. Another field of possible applications is yard switching and shunting where the speed is low but the average distance is approximately $1-2 \mathrm{~km}$.

In public transport several hybrids have been introduced (city buses, trams). Their power mission is well known and scheduled, thus the system design is very easy. Hybrid driven yard switchers and station shunting locomotives are forgotten except some prototypes in the Czech Republic (CKD 718.501, 1984, [6]), USA (GE Ecomagination, 2008 [7]), Canada (RailPower Green Goat 2009 [8]) and France (ALSTOM V200, 2010 [9]). The focus on hybrid shunting locomotives is motivated by another benefit of hybridization - diesel engine operation optimization.

\section{Power mission profile}

To optimize any operation and energy savings, power mission profile is needed to be well known. Dealing with shunting locomotives, their mission is not a regular or a repeating pattern of any

$$
\beta_{b}=\frac{\frac{1}{2} \cdot m \cdot \xi \cdot v_{b}^{2}-m \cdot g \cdot\left(p_{v(A V)}+p_{e, c}\right) \cdot l_{b}}{m \cdot g \cdot\left(p_{v()}+p_{e, c}\right) \cdot l_{b}+\frac{1}{2} \cdot m \cdot \xi \cdot v_{d}^{2}+m \cdot g \cdot\left(p_{v(A V)}+p_{e, c}\right) \cdot l_{d}}
$$

Where $A_{b}$ is computed for the braking period only, the $A_{t}$ represents a constant speed period and the $A_{r}$ represents the accelerating period of the train movement. It can be seen that (6) is a rolling stock dependent and nonlinear equation. Fig. 1 shows (6) in a chart $\beta_{b}=f(l, v)$ valid for a mixed wagons (passenger and freight) train with average acceleration $0.6 \mathrm{~m} / \mathrm{s}^{2}$. It should be noticed that the relative braking energy is higher for short distance and for higher speed trains. Most of the relative braking energy can be saved in an accumulator (flywheel, ultracapacitor, etc). To get the real energy savings or energy recuperated to the accumulator the efficiency should be considered.

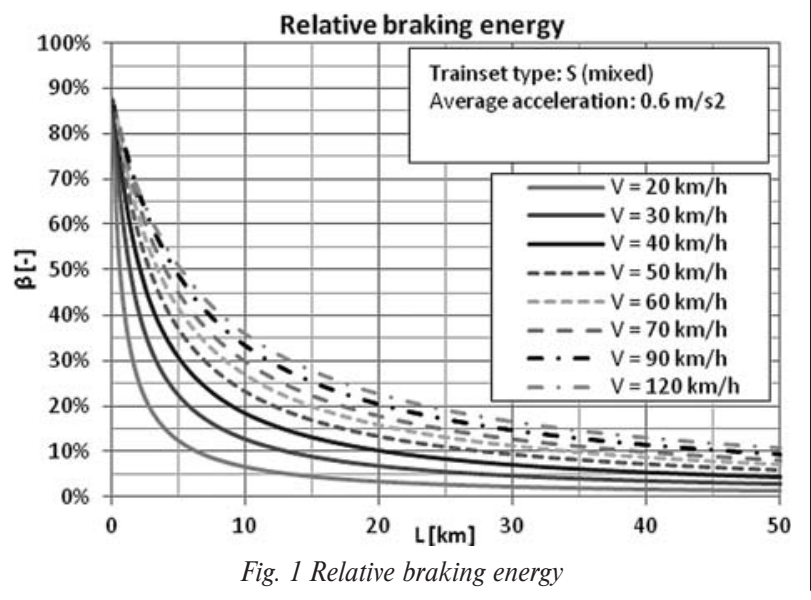

kind. Based on current needs the locomotive operates very randomly.

There is a common denominator in such missions operated by diesel locomotives: very low diesel power utilization. A long idling time stands side by side the short time full power operation intervals what causes higher specific fuel consumption and emissions [6]. The power demand is changing very fast and the system operates in steady state for a very short time, which only causes other losses.

\section{A. Shunting modes}

Heavy and light shunting operation can be recognized. Light shunting operation is a typical for stations and some industrial railways. The mission is to pick or drop wagons at sidings for loading and unloading. The acceleration and the speeds are usually higher due to operational reasons and allowed by the low weight of the trains.

Heavy shunting locomotives operate on yards and usually move a high load train sets between yards for or after the sorting, or sorting trains directly. Fig. 2 shows a typical heavy shunting operation in comparison to the light shunting operation. The speed uses to be lower (from 10 to $20 \mathrm{~km} / \mathrm{h}$ ) due to high load of the train.

To fully understand the mission a set of measurements and simulations were made and the results are introduced. 


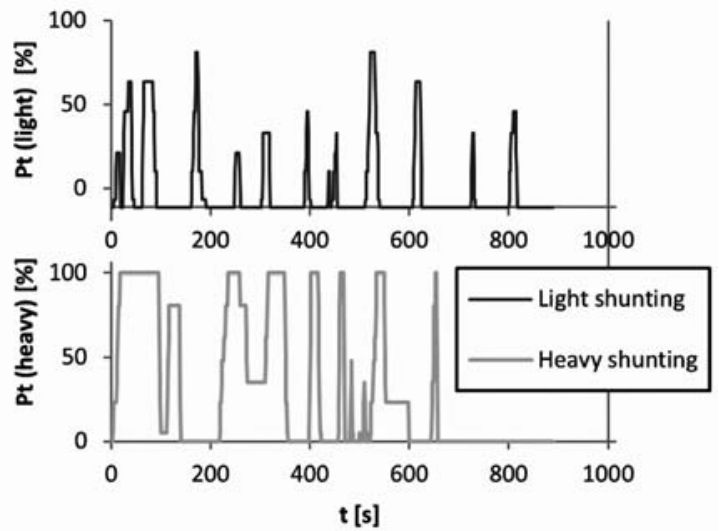

Fig. 2 Light and heavy shunting power mission comparison

\section{B. On-board Measurements}

On-board measurement is the most accurate way to get the real mission profile. The real world measuring well considers waiting periods, traffic interactions, weather conditions, coupling issues, etc. Therefore results are valuable for an analysis of power missions. A several days a week at least should be measured to capture irregularities.

For this purpose, several measurements were made in 2008 at OKD Transportation (today AWT Corporation) industrial railway in Kladno, Czech Republic, operated by 740.3 class locomotives [4]. The main mission consists of several shunting tasks nearby local mounting halls and freight train cars distribution from the central station to several companies placed within the industrial railway in Kladno. It can be characterized as a light shunting operation.

Parameters and results are summarized in Table 1. Data collection was realized with support of on-board control unit NES

On-Board Measurements summary

\begin{tabular}{|c|c|}
\hline Parameter & Value \\
\hline Axle arrangement & Bo'Bo' \\
Diesel engine & CAT C15 \\
Diesel power & $403 \mathrm{~kW}$ \\
Power transition & AC-DC \\
Weight & $64 \mathrm{t}$ \\
Gearbox ratio & $78: 15$ \\
Max. tractive effort & $230 \mathrm{kN}$ \\
Max. velocity & $60 \mathrm{~km} / \mathrm{h}$ \\
Cont. tractive effort & $114 \mathrm{kN}$ \\
Cont. speed & $8 \mathrm{~km} / \mathrm{h}$ \\
\hline Entire mission time (per day) & $6 \mathrm{hours}$ \\
Average speed & $4 \mathrm{~km} / \mathrm{h}$ \\
Average diesel power & $93 \mathrm{~kW}$ \\
Load range & $100-1100$ tons \\
Operation & Shunting, Short freight run \\
\hline
\end{tabular}

RV08 via diagnostic serial link. An example of one day power mission is shown in Fig. 3a. It should be noticed that the mission power average is $23.5 \%$ of the diesel engine rated power. Typical values of shunting locomotive power average are less than $15 \%$ in most cases, depending on power installed and the mission as well.

There is another issue with such a mission operated by diesel locomotive. Due to low speeds and short runs the power demand is changing very fast and the system cannot reach its steady state. Thus the diesel engine is not allowed to operate in optimal mode. All these indicators lead to a solution with diesel engine operating in a constant power mode described below supported with some kind of non-conventional power source.

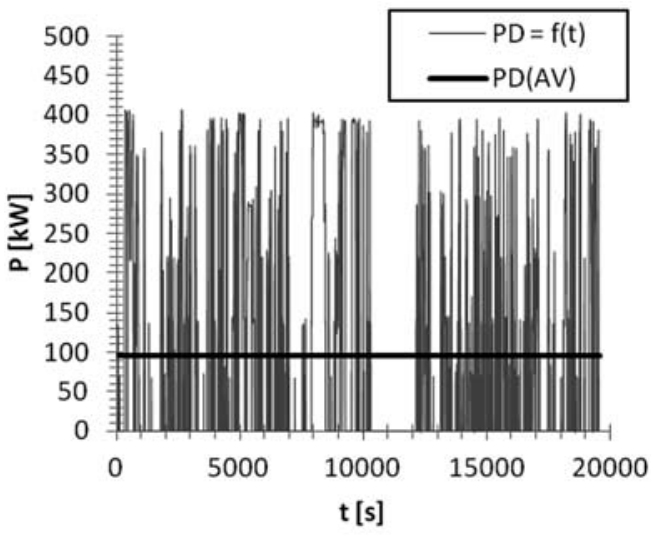

a)

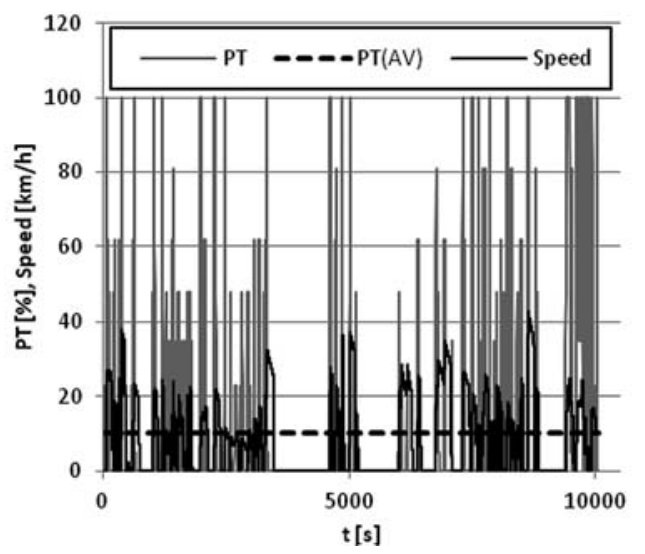

b)

Fig. 3 a) One-day power mission of 740.3 class; b) Power mission example of standard shunting

Such a mission represents an industrial light shunting operation with low average-to-maximum power ratio and high frequencies of power demand, which leads to higher specific consumption and higher emissions of the diesel engine.

To compare the industrial shunting with standard shunting mission, Figs. $3 \mathrm{a}$ and $3 \mathrm{~b}$ are introduced. The mission was recorded 
on 731 class with $600 \mathrm{~kW}$ diesel engine using a special data acquisition system on a standard light shunting mission in Kolín station. These two missions are nearly comparable but the power average. The speed shown in Fig. $3 \mathrm{~b}$ fits the high relative braking energy presumption from statement II.

Lower rated power of a diesel engine leads to its better average utilization. On the other hand, such a locomotive is not able to serve higher train loads.

The common sign of both records and the most of diesel locomotive operations is a very low power average represented by $P D(A V)$ in Fig. 3a and $P T(A V)$ in Fig. 3b.

Depending on a power mission, the average-to-maximum ratio is usually $40-70 \%$ for track missions and $10-20 \%$ for shunters. Similar results are presented in papers over the world.

Shunting missions cannot be operated by a low powered locomotive. The maximal diesel power is needed for acceleration and high load train shunting. Low power is requested when locomotive runs the train at constant speed. The rest is idling time needed when coasting or to keep the engine on optimal temperatures.

Dealing with low power average and high power peaks a conventional diesel driven locomotive cannot be optimized for shunting operations. Electrification of yards or industrial railways is very expensive and therefore out of discussion. With a hybrid drive technology a shunting locomotive operation can be optimized.

\section{Options of performance optimizations}

Based on power mission profile the optimization process can be divided into two separated aims. The first is to save energy losses when braking; the second aim is to optimize diesel engine operation and to lower fuel consumption and emissions. Both aims call for some kind of energy storage and additional power source. Therefore, a diesel-electric power transition combined with electric accumulator is discussed.

\section{A. Braking energy savings}

To save the braking energy expressed by (6), designed energy storage should be able to store it. The main problem is not in the amount of energy but in the short time the energy is produced the braking power. The braking power PB depends on demanded deceleration a, train speed $\mathrm{v}$ and its mass $\mathrm{m}(7)$

$$
P_{E}(t)=F_{B}(t) \cdot v(t)=m \cdot \xi \cdot \alpha(t) \cdot v(t)
$$

Where $F_{B}$ is a braking force and $\xi$ is a coefficient of rotational parts. There are three main limitations of electro-dynamic brake maximal braking power, maximal braking force and the brake fadeout in low speed. The final braking force is generated by electrodynamic brake in cooperation with conventional pneumatic brake.

Typical braking power values can be computed from accumulators' data shown in Table 2. Based on these values and typical accumulator parameters (Table 3), we can select the right accumulator type for the energy storage. Charging power allowed can be computed simply as

$$
\text { PCh }=\text { ChargingRatio } \cdot C
$$

Where ChargingRatio is a parameter from Table 2 and $C$ is capacity of the accumulator in $\mathrm{kWh}$. To utilize the most of the braking power, the accumulator should be sized according to (8). For example, $\mathrm{NiCd}$ accumulator can be charged with $2 \mathrm{C}$ [4], which means $500 \mathrm{kWh}$ for $1000 \mathrm{~kW}$ of braking power. Such an accumulator should weigh approximately 11.5 tons with $3.5 \mathrm{~m}^{3}$ of volume, which might be unsuitable for some locomotives. Considering the charging current or charging power, conventional accumulators are out of discussion. Modern $\mathrm{LiFePo}$ accumulators became very popular thanks to their specific parameters. In other words, $\mathrm{LiFePo}$ battery for $1000 \mathrm{~kW}$ and $500 \mathrm{kWh}$ weighs about 5 tons with $1.5 \mathrm{~m}^{3}$ of volume. The main disadvantage of LiFePo accumulators is a high price [4].

Typical accumulator data comparison [5]

\begin{tabular}{|c|c|c|c|c|c|c|}
\hline Parameter & Note & $\mathrm{NiCd}$ & $\mathrm{NiMH}$ & LiFePo & $\mathrm{NiNaCl}$ & SC \\
\hline \multirow[t]{3}{*}{ Cell Voltage [V] } & Nom. & 1.2 & 1.2 & 3.2 & 2.58 & 2.5 \\
\hline & Min & 0.85 & 0.85 & 2.5 & & 0 \\
\hline & $\operatorname{Max}$ & 1.85 & 1.85 & 4.25 & 2.7 & 2.5 \\
\hline \multicolumn{2}{|c|}{ Specific Energy [Wh/kg] } & 45 & 70 & 100 & 100 & 5 \\
\hline \multicolumn{2}{|c|}{ En. Density [Wh/l] } & 150 & 230 & 330 & 172 & 0.07 \\
\hline \multicolumn{2}{|c|}{ Spec. Power $[\mathrm{W} / \mathrm{kg}]$} & 60 & 150 & 720 & 170 & 2000 \\
\hline \multirow[t]{2}{*}{ Efficiency } & $\begin{array}{l}\text { Amper- } \\
\text { hour }\end{array}$ & 0.8 & 0.99 & 0.99 & 0.99 & 0.99 \\
\hline & $\begin{array}{l}\text { Watt- } \\
\text { hour }\end{array}$ & 0.6 & 0.96 & 0.96 & 0.98 & 0.98 \\
\hline \multirow{2}{*}{$\begin{array}{l}\text { Discharg. } \\
\text { Ratio }\left[\mathrm{h}^{-1}\right] /[\mathrm{A}]\end{array}$} & Cont. & $1 \mathrm{C}$ & $2 \mathrm{C}$ & $3 \mathrm{C}$ & $1 \mathrm{C}$ & $150 \mathrm{~A}$ \\
\hline & Pulse & $3 \mathrm{C}$ & $20 \mathrm{C}$ & $20 \mathrm{C}$ & $4 \mathrm{C}$ & $750 \mathrm{~A}$ \\
\hline \multirow{2}{*}{$\begin{array}{l}\text { Charging } \\
\text { Ratio }\left[\mathrm{h}^{-1}\right] /[\mathrm{A}]\end{array}$} & Cont. & $0.5 \mathrm{C}$ & $0.5 \mathrm{C}$ & $0.5 \mathrm{C}$ & - & $150 \mathrm{~A}$ \\
\hline & Fast & $2 \mathrm{C}$ & $1 \mathrm{C}$ & $2 \mathrm{C}$ & $2 \mathrm{C}$ & $750 \mathrm{~A}$ \\
\hline \multirow[t]{2}{*}{ Temp. $\left[{ }^{\circ} \mathrm{C}\right]$} & Min & -40 & -20 & -45 & -40 & -40 \\
\hline & $\operatorname{Max}$ & 45 & 50 & 85 & 50 & 65 \\
\hline $\begin{array}{l}\text { Life time } \\
\text { [cycles] }\end{array}$ & $\begin{array}{c}\text { At } 80 \% \\
\text { DOD }\end{array}$ & 3500 & 4500 & 5000 & 2000 & 1E6 \\
\hline \multicolumn{2}{|l|}{$\begin{array}{l}\text { Approx. Price } \\
\text { [USD/Wh] }\end{array}$} & 1.5 & 4.3 & 6.5 & 150 & 80 \\
\hline
\end{tabular}

Table 2

To reduce the accumulator size, a supercapacitor can be used. In this case, charging power is limited by the maximal current only and the supercapacitor is sized according to the kinetic energy of the typical train load. Stored energy helps with the next acceleration, thus the diesel can be undersized. The main disadvantage is low energy density and pricing. Due to dimension limitations, the capacity is limited to approximately $10 \mathrm{kWh}$ for most of locomo- 
tives [4]. This amount of energy can help with acceleration but it cannot fit high loaded train moves between yards where the full power is needed for minutes. Thus supercapacitors are suitable for very specific applications with well-known periodic start-stop cycle e.g. city buses, trams and light trains. Nevertheless, there is a project coming that will introduce a hybrid shunting locomotive with a supercapacitor of $6 \mathrm{kWh}$ of energy [10]. The results will be presented in future publications.

\section{B. Diesel engine performance optimization}

On shunting locomotives, diesel engine operates at idle most of time and at low power with short time power peaks, as mentioned above. This leads to higher specific consumption and low efficiency [4].

Hybrid technology can help to solve this issue. Accumulator serves as a peak source with sufficient capacity to cover usual missions. Then, diesel engine can be undersized to overall power average of the mission. Such a design brings additional costs of the accumulator but the undersized diesel engine can partially compensate these costs and bring many advantages such as lower fuel consumption. There are other advantages of the hybrid drive, such as recuperative braking, silent or zero emission operation, etc. The most common hybrid concept for railway applications is Full Hybrid with series configuration and it can be found e.g. in RailPower project Green Goat [8]. In moder hybrid concept the AC traction drive should be used to improve overall efficiency [11]

To demonstrate these advantages, a hybrid vehicle simulation model was designed and analyzed and presented in [5]. The analysis is based on power mission from Kladno industrial railway and serves as an example of predesign of hybrid vehicles. The main results and a very brief description of the design method are introduced.

\section{Hybrid vehicle design}

There are several methods for hybrid vehicle design based on different attitudes. The very basic method, Power average method, introduced e.g. in [6] is based on the average of the mission power. Therefore the mission power time record should be known. The diesel engine is than undersized but with a sufficient power to move the train in case of the accumulator failure. Results of such a design have been introduced in 1980's with TA436 class CKD hybrid locomotive design [6].

Considering the time-power mission record is a time signal, it can be transformed by FFT (fast Fourier transform) and used for the hybrid drive design. The constant part of the signal is the power demand for the diesel engine, the rest of the power demand signal is divided based on the low-pass filter between the accumulator and supercapacitor. This method was published in [12] and [13].

The hybrid drive design is a multi-point optimization problem, thus evolutionary algorithms can be used. The use of particle swarm optimization [14] for the hybrid vehicle design was introduced in [5]. The cost function (correctness of the solution) is not a classic function, but it is a simulation model running with the real-world data. Overall analysis of the simulation is used to evaluate each step of the optimization process and the results are for the next step. Parameters of the final design are shown in Table 3.

The system uses the accumulator as the main power source, up to $576 \mathrm{~kW}$. In the meantime the diesel operates on the average power of $50 \mathrm{~kW}$. If the power demand is higher, the diesel engine power is set to full (up to $224 \mathrm{~kW}$ ). If the battery state-of-charge is low, the diesel power rises slowly to charge the battery and to replace the battery in the role of the traction power source.

This concept can significantly lower the fuel consumption: from 9 to $16 \mathrm{~kg}$ per day [4]. Operating on the optimal power, the diesel engine emissions are lower. With recuperation, energy saving is up to $70 \%$ for every acceleration.

\section{Return on investment}

The supercapacitor increases input costs as mentioned above, thus the usage is optional and depends on the target application. In the following balance the supercapacitor is not considered.

Balancing the costs, fuel pricing is one of the most important factors. Nevertheless, the fuel costs are hardly predictable but the trend can be estimated based on the long term statistics [16].

Input costs can be compared with a conventional vehicle of similar performance and expressed as the additional costs of hybrid

\begin{tabular}{|l|l|l|l|}
\hline Component & Parameters & Component & Parameters \\
\hline Diesel engine & CAT C7 $(157-224 \mathrm{~kW})[15]$ & Supercapacitor (optional) & Type: Maxwell BMOD0094 \\
\hline Accumulator & Type: Saft NHP $10-100$ & & \\
& NiMH, $100 \mathrm{Ah} / 576 \mathrm{~V}$ & & Charging: $600 \mathrm{~kW}$ \\
& Charging: $70 \mathrm{~kW}$ & & Discharging: $600 \mathrm{~kW}$ \\
& Discharging: $576 \mathrm{~kW}$ & & Mass: $600 \mathrm{~kg}$ \\
& Mass: $893 \mathrm{~kg}$ & & \\
& No. of units : 48 & & \\
\hline
\end{tabular}


drive components. Considering the life-time of the accumulator (usually 5 years) and the fuel savings computed in the previous part.

Balance of the hybridization in 30 years is introduced in [4] In the diesel performance optimization the costs can be returned in 24 years. Considering the energy savings due to the recuperation of the braking energy the investments can be paid back in 19 years. Such a long term return on investments is not ideal at all. But the prognosis of the fuel price gives the hybrid drive technology good position for the future. With the accumulator and supercapacitor technology development the costs of hybrid drive should lower the initial investments [5].

\section{Conclusion}

Hybrid technology is a great possibility to eliminate braking energy losses and to optimize internal combustion engine operation.

Based on the longitudinal analysis, the braking energy savings can be up to $70 \%$ of the overall energy during one start-stop cycle. Unfortunately, present electro-chemical accumulators are not suitable for the energy storage of such energy due to its low charging power limitation. Therefore, supercapacitors should be used.
Many diesel locomotives operating yards, station shunting and industrial railways missions must deal with high power peaks and long-term idling periods. This leads to non-optimal power utilization, higher fuel consumption and higher emissions. To optimize diesel engine operation, the accumulator should be used as a power peak source. The diesel engine can operate on its optimal power with the lowest specific fuel consumption. Instead of idling, the accumulator is pre-charged.

Hybrid locomotive design can be supported by computer technology and modern methods such as Particle swarm method. Based on simulations, performance parameters can be optimized off-line before the real locomotive is finished.

Although the costs of modern accumulators are still high, the hybrid drive technology should be considered as the future of city transport and some specialized operations such as yard switching and shunting. For the present implementation the return on investments should be measured in two tens of years.

\section{Acknowledgment}

We would like to thank to CZ LOKO Company for the support and help with the design. Measurements were made thanks to AWT Kladno support.

\section{References}

[1] BARRERO, R., MIERLO, J. V., TACKOEN, X.: Energy Savings in Public Transport, IEEE Vehicular Technology Magazine, vol. 3, pp. 26-36, Sep. 2008. ISSN 1556-6072

[2] IWNICKI, S.: Handbook of Railway Dynamic, CRC Press, Taylor \& Francis. New York, 2006. ISBN 978-0-8493-3321-7

[3] CENE, B., RADOSAVLJEVIC, A., GAVRILOVIC, B.: Driving Energy Consumption of Electric Traction Vehicles. Communications - Scientific Letters of the University of Zilina, No. 3, pp. 50-56, 2008. ISSN 1335-4205

[4] PACHA, M.: Hybrid Propulsion of Railway Vehicles, PhD. Thesis, University of Zilina, Slovakia, 2010.

[5] PACHA, M., STEPANEK J.: Energy Savings and Performance Optimizations of Hybrid Shunting Locomotives. Proc. of 2012 Elektro, University of Zilina, 2012. ISBN 978-1-4673-1178-6

[6] POHL, J.: Hybridní pohon posunovací lokomotivy / Hybrid Driven Shunting Locomotives, CKD Report, 1982. unpublished.

[7] GE transportation - North America. [Online]. http://www.getransportation.com, 2009, Feb. [cit. 2012-12-05]

[8] COUSINEAU, R.: Development of a Hybrid Switcher Locomotive, IEEE Instrumentation \& Measurement Magazine, pp. 25-29, Feb. 2006. ISSN 1094-6969

[9] Alstom. Hybrid Loco, A New Environmental-friendly Concept for Shunting. [online] http://www.transport.alstom.com, 2010, May. [cit. 2012-12-06]

[10] I-mash, Трансмашхолдинг работает над созданием гибридного тепловоза с асинхронным тяговым приводом /Transmash Holding is Working on Hybrid Locomotive with AC Traction Drive, [online] http://www.i-mash.ru, 2011, Feb. [cit. 2012-12-17]

[11] KUCHTA, J., FULIER, M.: Electrical Transmission of Modernized Locomotives of Independent Traction Power, Communications - Scientific Letters of the University of Zilina, No. 2-3, pp. 76-88, 2001. ISSN 1335-4205

[12] AKLI, C. R., ROBOAM, X., JEUNESSE, A.: Energy Management and Sizing of a Hybrid Locomotive, Power Electronics and Applications, 2007 European Conference, pp. 1-10, 2007, [Online]. http://www.ieee.org, 2007. [cit. 2010-05-20], E-ISBN 978-92-75815-10-8

[13] JAAFAR, A., AKLI, C. R., SARENI, B., ROBOAM, X., JEUNESSE, A.: Sizing and Energy Management of a Hybrid Locomotive Based on Flywheel and Accumulators, Transactions on Vehicular Technology, vol. 58, No. 8, pp. 3947-3957, Oct. 2009. ISSN 0018-9545

[14] ZELINKA, I., OPLATKOVA, Z., SEDA, M., OSMERA, P., VCELAR, F.: Evolucni vypocetni techniky - principy a aplikace / Evolutionary Computation - Principles and Applications (in Czech), Prague : BEN, 2009. ISBN 80-7300-218-3

[15] Caterpillar. [Online]. http://www.cat.com. 2009, Feb. [cit. 2012-12-18]

[16] EIA. Energy Information Administration. [Online]. http://tonto.eia.doe.gov. 2010, May. [cit. 2010-05-20] 